\title{
High-affinity transport, cyanide-resistant respiration, and ethanol production under aerobiosis underlying efficient high glycerol consumption by Wickerhamomyces anomalus
}

\author{
Aureliano Claret da Cunha ${ }^{1}$ - Lorena Soares Gomes ${ }^{1}$. Fernanda Godoy-Santos ${ }^{1}$ - Fábio Faria-Oliveira ${ }^{1}$. \\ Janaína Aparecida Teixeira ${ }^{1}$. Geraldo Magela Santos Sampaio ${ }^{1}$. Maria José Magalhães Trópia ${ }^{1}$. \\ leso Miranda Castro ${ }^{1}$. Cândida Lucas ${ }^{2} \cdot$ Rogelio Lopes Brandão $^{1}(1)$
}

Received: 24 July 2018 / Accepted: 19 December 2018 / Published online: 24 January 2019

(c) Society for Industrial Microbiology and Biotechnology 2019

\begin{abstract}
Wickerhamomyces anomalus strain LBCM1105 was originally isolated from the wort of cachaça (the Brazilian fermented sugarcane juice-derived Brazilian spirit) and has been shown to grow exceptionally well at high amounts of glycerol. This paramount residue from the biodiesel industry is a promising cheap carbon source for yeast biotechnology. The assessment of the physiological traits underlying the W. anomalus glycerol consumption ability in opposition to Saccharomyces cerevisiae is presented. A new $\mathrm{WaStl} 1$ concentrative glycerol- $\mathrm{H}^{+}$symporter with twice the affinity of $S$. cerevisiae was identified. As in this yeast, WaSTL1 is repressed by glucose and derepressed/induced by glycerol but much more highly expressed. Moreover, LBCM1105 aerobically growing on glycerol was found to produce ethanol, providing a redox escape to compensate the redox imbalance at the level of cyanide-resistant respiration (CRR) and glycerol 3P shuttle. This work is critical for understanding the utilization of glycerol by non-Saccharomyces yeasts being indispensable to consider their industrial application feeding on biodiesel residue.
\end{abstract}

Keywords Wickerhamomyces anomalus · Glycerol metabolism · Cachaça $\cdot$ Biotechnological applications · Glycerol transport $\cdot$ STL1

\section{Introduction}

Glycerol is aby-product of biodiesel production processes. The transesterification reaction, using vegetable oils or animal fats and alcohol, produces stoichiometrically $10 \%$ of crude glycerol per weight of the oils consumed [37]. Crude glycerol contains mostly glycerol $(35-50 \%)$, in addition to water (10-30\%), methanol (20-50\%), and sulfuric acid (5-10\%), as well as small amounts of $\mathrm{NaCl}$ and several types

Rogelio Lopes Brandão rlbrand@nupeb.ufop.br

1 Laboratório de Biologia Celular e Molecular, NUPEB, Universidade Federal de Ouro Preto, Campus do Morro do Cruzeiro, Ouro Preto, MG 35.400-000, Brazil

2 Instituto de Ciência e Inovação em Bio-Sustentabilidade (IB-S)/Centro de Biologia Molecular e Ambiental (CBMA), Universidade do Minho, Braga, Portugal of fatty acids and impurities. Actually, its composition differs depending on the alcohol/oil ratio and the catalytic agent employed [17]. In view of the global biodiesel market boost [23, 46], the worldwide production of crude glycerol is currently growing enormously. For example, in Brazil, the consumption of biodiesel was predicted to increase up to 4 billion liters per year in 2022, 40\% more than in 2013 [5], which could be highly underestimated, because the percentage of biodiesel added to common diesel is also predicted to double in the same period [6]. Therefore, Brazil alone is predicted to produce by then 400 million liters of crude glycerol per year. Although glycerol is a compound that is widely used in numerous industrial processes and products and the price of glycerine (a commercial term for a sample containing more than $95 \%$ glycerol) has fallen dramatically [75], the heterogeneous and mixed nature of crude glycerol precludes its direct use in industry [1]. As a result, crude 
glycerol faces problems of proper disposal [47] and environmental impact [33] and demands acceptable solutions [17].

Using glycerol for microbial growth and the subsequent production of value-added products by single-cell factories would be ideal to improve the ecological sustainability of the biofuel industry while contributing to its economic viability [75]. Crude glycerol has been shown to be usable as a substrate by bacteria, fungi, and yeasts producing diverse chemicals and polymers (reviewed in [25]). In particular, lipolytic yeast strains from the genera of Lipomyces, Rhodotorula, and Yarrowia have been shown to produce single-cell fine oils [32, 34, 63], whereas the xylose consumer Pachysolen tannophilus produced $28.1 \mathrm{~g} \mathrm{~L}^{-1}$ of ethanol from crude glycerol. Therefore, the identification of new wild strains that are able to grow and/or to produce different substances of biotechnological interest from this substrate is highly justifiable.

The microflora from the spontaneous fermentation underlying the production of cachaça (the Brazilian sugarcanederived spirit) is highly diverse $[9,19]$. In a previous survey on the physiological traits of more than 100 different yeasts isolated from the wort of cachaça, a robust isolate of Wickerhamomyces anomalus LBCM1 105 (previously LBCM105 [9]) was identified, which could grow on $25 \%$ glycerol (reagent-grade). W. anomalus was formerly designated as Pichia anomala, Hansenula anomala, or Candida pelliculosa. It is mostly known for being a wine spoilage yeast $[44,49]$ and has been isolated from several habitats frequently associated with spoilage or processing of food and grain products [50]. Nevertheless, under its several aliases, W. anomalus has been suggested as an interesting cell factory for the production of aromas for alcoholic beverages [27], biosurfactants [62], lipids [2, 61], enzymes [12, 21], and bread [41, 71]. Importantly, it has been shown to produce ethanol from glucose, sucrose, or xylose [9]. In line with this metabolic versatility, $W$. anomalus can grow on very diverse carbon or nitrogen sources, at both high and low $\mathrm{pH}$, under osmotic stress/low $a_{w}$ and anaerobic conditions [16].
The efficient use of a substrate is the first step to consider any microorganism as a putatively economic viable biotechnological tool [66]. This depends not only on fast and tightly regulated metabolism, but also on an efficient transport system that can generously supply progressing metabolic fluxes without drowning the cell. This work was aimed at a first assessment of the W. anomalus LBCM1105 glycerol consumption ability. A new STL1 gene was identified, WaSTL1. WaStl1 was shown to work as a glycerol- $\mathrm{H}^{+}$symporter with more than twice the affinity of the $S$. cerevisiae counterpart, and WaSTL1 was shown to be identically repressed by glucose and derepressed/induced by glycerol, albeit in considerably larger amounts. Moreover, the growth of W. anomalus on glycerol was accompanied by the aerobic production of ethanol, most probably providing redox compensation for cyanide-resistant respiration (CRR). More efficient glycerol utilization, therefore, appears to derive not only from the high-affinity character of WaStll permease combined with a higher expression of WaSTL1, but also from displaying aerobic ethanol production. The present work paves the way for a better understanding of the metabolism of $W$. anomalus, as well as of the possibility of optimizing its growth on glycerol wastes for industrial applications.

\section{Materials and methods}

\section{Microbial strains and cultivation conditions}

The microbial strains used in this study are listed in Table 1. Yeasts were grown at $30{ }^{\circ} \mathrm{C}$ on YP $(1 \%$ yeast extract, $2 \%$ peptone) or YNB without amino acids (HiMedia, Mumbai, India). Amino acids were added as previously described [58]. The YNB media were prepared in a citrate/phosphate buffer (for 1 L: $614.5 \mathrm{~mL}$ of $0.1 \mathrm{M}$ citric acid $+385.5 \mathrm{~mL}$ of $0.2 \mathrm{M} \mathrm{Na}_{2} \mathrm{HPO}_{4}$ ), adjusted to a $\mathrm{pH}$ value of 4.0 for liquid and 6.5 for solid media. Batch cultures were preinoculated

Table 1 Biological materials used in this study

\begin{tabular}{|c|c|c|}
\hline Strain & Genotype & Origin \\
\hline \multicolumn{3}{|l|}{ Wickerhamomyces anomalus: } \\
\hline LBCM1105 wt & Isolate from cachaça wort & Conceição et al. [9] \\
\hline \multicolumn{3}{|l|}{ Saccharomyces cerevisiae: } \\
\hline BY4741 wt & MATa; ura3 $\Delta 0 ;$ leu $2 \Delta 0 ;$ his $3 \Delta 1 ;$ met $15 \Delta 0$ & Euroscarf \\
\hline BY4741 $\Delta s t l 1$ & 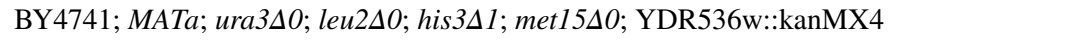 & Euroscarf \\
\hline BY4741 $\Delta$ stll pCevhph & 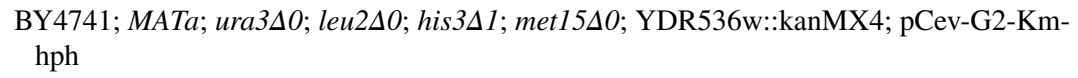 & This study \\
\hline BY4741 $\Delta$ stl1 pCevWaSTL1 & 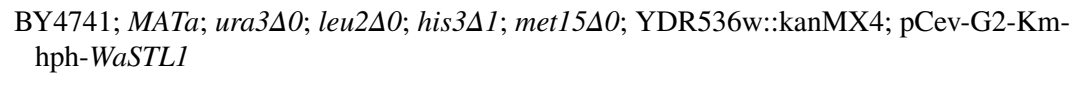 & This study \\
\hline \multicolumn{3}{|l|}{ E. coli: } \\
\hline TOP10 & 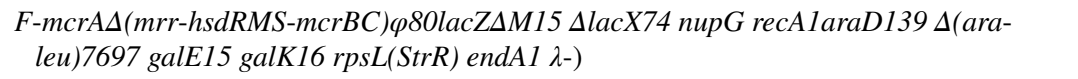 & Invitrogen (NL) \\
\hline
\end{tabular}


into $20 \mathrm{~mL}$ of YNB or YP and $0.3 \%$ glucose for $12 \mathrm{~h}$, centrifuged, and then washed in a citrate/phosphate buffer and resuspended in $5 \mathrm{~mL}$. This was used to set OD 0.1 inoculum in a $50 \mathrm{~mL}$ medium with $3,5,10$, or $20 \%$ glycerol or $2 \%$ glucose, at an air/liquid ratio of 5:1. Incubation took place at $30{ }^{\circ} \mathrm{C}$ with $200 \mathrm{rpm}$ orbital shaking. Growth was quantified by measuring $\mathrm{OD}_{600 \mathrm{~nm}}$. Escherichia coli $\mathrm{TOP} 10$ was maintained in a Luria-Bertani (LB) medium $(0.5 \%$ yeast extract, $1 \%$ tryptone, and $1 \% \mathrm{NaCl}$ ) and grown at $37{ }^{\circ} \mathrm{C}$ with $200 \mathrm{rpm}$ orbital shaking. Solid media had $2 \%$ agar. All concentrations mentioned in $\%$ correspond to $\mathrm{w} / \mathrm{v}$.

\section{High-performance liquid chromatography (HPLC) analysis}

Glycerol and ethanol in the growth media were quantified using HPLC (Shimadzu, Kyoto, Japan), equipped with an autosampler (SIL-20ACHT, Shimadzu), a binary pump (LC20AD, Shimadzu), a column oven (CTO-20A, Shimadzu), a refractive index detector (RID-10A, Shimadzu), and a $300 \times 7.8 \mathrm{~mm}, 9 \mu \mathrm{m}$ particle-size column (Aminex HPX$87 \mathrm{H}$; Bio-Rad, Hercules, CA, USA). A mobile phase of $2.5 \mathrm{mM} \mathrm{H}_{2} \mathrm{SO}_{4}$ was used. Runs were performed at $55^{\circ} \mathrm{C}$ for $30 \mathrm{~min}$ at a flow rate of $0.6 \mathrm{~mL} \mathrm{~min}^{-1}$. The injection volume for all samples was $30 \mu \mathrm{L}$. Samples of yeast culture $(1.5 \mathrm{~mL})$ were collected and centrifuged (13,000 rpm, $3 \mathrm{~min})$, and then, the supernatant was stored at $-20^{\circ} \mathrm{C}$. Prior to injection, the samples were filtered through a $0.22 \mu \mathrm{m}$ filter and diluted appropriately in ultrapure water.

\section{General molecular biology procedures}

Yeast genomic DNA was extracted as previously described [35]. Polymerase chain reaction (PCR) was performed using a T100 thermocycler (Bio-Rad, CA, USA) and GoTaq ${ }^{\circledR}$ DNA Polymerase (Promega, Madison, WI, USA) according to the manufacturer's protocol. Primers (Table 2) were synthesized by Integrated DNA Technologies (IDT Corporation, Newark, NJ, USA). Yeast strains were transformed using the lithium acetate-polyethylene glycol method as previously described [10] and E. coli by $\mathrm{CaCl}_{2} /$ heat-shock-based protocol [3]. PCR products were purified and sequenced using capillary electrophoresis (Sanger's method) using the ABI3130 platform from Life Technologies (Myleus Biotecnologia, Belo Horizonte, MG, Brazil). Plasmids from $E$. coli were purified using a Wizard ${ }^{\circledR}$ Plus SV Minipreps DNA Purification System (Promega, WI, USA).

\section{Amplification of the STL1 Gene in W. anomalus}

Degenerate primers for STL1 (Table 2) were designed according to the conserved amino acid sequences of the Stl1 predicted proteins from the following NCBI accession numbers: S. cerevisiae P39932, Millerozyma farinosa XP_004195829.1, Candida albicans EEQ 46634, and Scheffersomyces stipitis ABN65745. The amplified fragment was purified, sequenced, and compared in silico against the genome of $W$. anomalus LBCM1105 available at CTBE (Brazilian Bioethanol Science and Technology Laboratory, Campinas, SP, Brazil) [53, 57]. The obtained chromosomal alignment of WaSTL1 was used to design specific primers (Fw_WaSTL1 and Rv_WaSTL1 in Table 2), which allowed the amplification of the full open-reading frame (ORF).

\section{In silico analysis of WaStl1p}

The comparative analysis of amino acid sequences from WaStllp and $S c$ Stllp was performed using SnapGene ${ }^{\circledR}$

Table 2 Primer sequences used in this study

\begin{tabular}{ll}
\hline Primers & Sequence $\left(5^{\prime}-3^{\prime}\right)$ \\
\hline Fw_WaSTL1_degen & GGTTATGATCAAGGT \\
Rv_WaST1_degen & ACCAGCAGTTTCTGG \\
Fw_WaSTL1 & ATGGGTTTTGATTGGAAAT \\
Rv_WaSTL1 & TTAAACATTATCATCACCTTTTTTAAC \\
Fw_hph_ho_pCev & AACTTCGTATAATGTATGCTATACGAAGTTATTAGGTGATGTGGTCGGCTGGAGATCGG \\
Rv_hph_ho_pCev & TTCTCAGGTATAGCATGAGGTCGCTCCTAGTGGATCTGATCAGTATAGCGACCAGCATTC \\
Fw_WaSTL1_ho_pCev & AGGATCCGTAATACGACTCACTATAGGGCCCGGGCGTCGAATGGGTTTGATTGGAAATC \\
Rv_WaSTL1_ho_pCev & TCGAGGTCTTCTTCGGAAATCAACTTCTGTTCCATGTCGATTAAACATTATCATCACCTT \\
Fw_ACT1_qPCR & CGTCTGGATTGGTGGTTCT \\
Rv_ACT1_qPCR & GTGGTGAACGATAGATGGAC \\
Fw_ScSTL1_qPCR & CAAGGGTTGATGGCAAGTCT \\
Rv_ScSTL1_qPCR & CCTGCACTACAGTTGCGTGT \\
Fw_WaSTL1_qPCR & ACCGCCACTATTCCAGTTTG \\
Rv_WaSTL1_qPCR & TGAACCTTCCAAGTTGACCA \\
\hline
\end{tabular}


software Version 2.3.2 (Chicago, IL, USA) software. The "alternative yeast nuclear" codon usage was assumed for $W$. anomalus. The amino acid sequence alignment was performed by Clustal (using default parameters). Several servers were used to predict the hydropathy profile and therein the topology of WaStllp putative transmembrane nature: HMMTOP 2.0 (Hidden Markov Model for Topology Prediction) [68], available at http://www.enzim.hu/hmmtop/; TMHMM v.2.0 (membrane protein topology prediction method, based on a hidden Markov model) [26], available at http://www.cbs.dtu.dk/services/TMHMM/; PredictProtein (online prediction of proteins' structural and functional features) [74], available at http://www.predictprotein.org/; HHpred (a server for protein remote homology detection and 3D structure prediction) [76], available at https://toolk it.tuebingen.mpg.de/\#/tools/hhpred; PSIPRED (Protein Sequence Analysis Workbench) [7], available at http://bioin f.cs.ucl.ac.uk/psipred/?memsatsvm $=1$. Ortholog prediction was performed using egg NOG 4.5 [22], available at http:// eggnogdb.embl.de/\#/app/home.

\section{Vector construction and yeast transformation}

The pCEV-G2-Km plasmid was a gift from Lars Nielsen and Claudia Vickers (Addgene plasmid \#46815) [70]. This plasmid has TEF1 and PGK1 promoter-controlled expression cassettes associated with geneticin (G418) resistance. To add hygromycin (hph) resistance, the corresponding cassette hphMX6 was amplified from the pJET1,2-attB-hph-attP plasmid [72] using Fw_hph_ho_pCev and Rv_hph_ho_pCev primers (Table 2). An amplicon was used to transform $S$. cerevisiae BY4741 by homologous recombination together with EcoRV digested pCEV-G2-Km [10], and pCevhph was obtained. The same strategy was used to generate pCevWaSTL1, but pCEV-G2-Km was digested with EcoRV and Sall instead. WaSTL1 was amplified with specific primers (primers Fw_WaSTL1_ho_pCev and Rv_WaSTL1_ho_pCev in Table 2). Transformants were selected for resistance to $500 \mu \mathrm{g} \mathrm{mL}^{-1}$ hygromycin (Cayman Chemical, Ann Arbor, MI, USA). Figure 1 illustrates the strategy used for plasmid construction. Plasmids were rescued from yeasts as described by Singh and Weil [60] and then amplified in $E$. coli according to the standard procedures [3]. Transformants were selected in $100 \mu \mathrm{g} \mathrm{mL}^{-1}$ ampicillin (MIDSCI, Valley Park, MO, USA). The correctness of the constructions was checked by PCR; restriction analysis using KpnI, BamHI, and SpeI enzymes; sequencing.

\section{RNA extraction and CDNA synthesis}

Total RNA was extracted from $100 \mathrm{~mL}$ of a yeast culture in the middle log growth phase. The cells were centrifuged and the total RNA was extracted using the phenol/chloroform method. The concentration of each RNA sample was measured using the NanoDrop 2000 Spectrophotometer (Thermo Fisher Scientific, Waltham, MA, USA). Reverse transcription of RNA and cDNA synthesis was carried out using the High-Capacity cDNA Reverse Transcription Kit (Applied Biosystems, Foster City, CA, USA). Briefly, $0.1 \mu \mathrm{g}$ of each total RNA sample was reverse-transcribed using random primers and MultiScribe ${ }^{\mathrm{TM}}$ Reverse Transcriptase according to the manufacturer's instructions and then stored at $-20{ }^{\circ} \mathrm{C}$. Prior to the cDNA synthesis, a DNase treatment was performed using RQ1 RNase-free DNase according to the manufacturer's instructions (Promega).

\section{RT-qPCR procedures}

RT-qPCR was performed on an ABI 7500 Fast Real-Time PCR System (Applied Biosystems, CA, USA) using the SYBR Green Master Mix Kit (Applied Biosystems, CA, USA). For each reaction of a $20 \mu \mathrm{L}$ final volume, $10 \mu \mathrm{L}$ of SYBR Green Master Mix 2X, $1 \mu \mathrm{L}$ of both oligonucleotides $(10 \mu \mathrm{M} F w / R v), 6 \mu \mathrm{L}$ of DEPC water, and $2 \mu \mathrm{L}$ of cDNA were used. The plate was sealed and centrifuged. The reaction proceeded as follows: one cycle of $2 \mathrm{~min}$ at $50^{\circ} \mathrm{C}$, one cycle of $10 \mathrm{~min}$ at $95^{\circ} \mathrm{C}, 40$ cycles of $15 \mathrm{~s}$ at $95^{\circ} \mathrm{C}$ and $1 \mathrm{~min}$ at $60^{\circ} \mathrm{C}$, and one cycle of $1 \mathrm{~min}$ at $60^{\circ} \mathrm{C}$. The primers used are listed in Table 2. The tests for amplification efficiency and validation of the experiments were performed as described previously [52]. The expression level of the STL1 target gene was normalized according to the constitutive $A C T 1$ gene. For each sample (in triplicate); the value of the quantitative relative expression in 5\% glycerol was determined as $2^{-\Delta \Delta C_{\mathrm{t}}}$ regarding the STL1 gene with reference to BY4741 or LBCM1105 expression in $2 \%$ glucose.

\section{Measurement of glycerol initial uptake rates}

Glycerol transport was characterized as previously described $[28,29,36]$ with some adaptations. Radiolabeled $\left[{ }^{14} \mathrm{C}\right]$ glycerol (Amersham, Freiburg, Germany) was used. Cells were harvested at the exponential growth phase, double-washed with ultrapure water, washed again with $100 \mathrm{mM}$ Tris/citrate buffer $(\mathrm{pH}=5.0)$, and then resuspended in the same buffer at a final concentration of $\sim 10 \mathrm{mg} \mathrm{mL}^{-1}$ (dry weight). The glycerol initial uptake rates of $10 \mathrm{~s}$ were determined in the same buffer. The glycerol concentrations ranged from 0.05 to $5 \mathrm{mM}$, and the radiolabel-specific activities (SAs) ranged from 30 to $60 \mathrm{GBq} \cdot \mathrm{mol}^{-1}$. All assays were carried out in duplicate. To test the active nature of WaStl1-mediated glycerol transport and its dependence on the proton motive force (p.m.f.), cells were incubated for $10 \mathrm{~s}$ on a $4 \mu \mathrm{M}$ carbonyl cyanide $m$-chlorophenylhydrazone (CCCP) ionophore prior to the transport assay. Under these conditions, transport was assayed using $0.2,2$, and $5 \mathrm{mM}\left[{ }^{14} \mathrm{C}\right]$ glycerol. The 


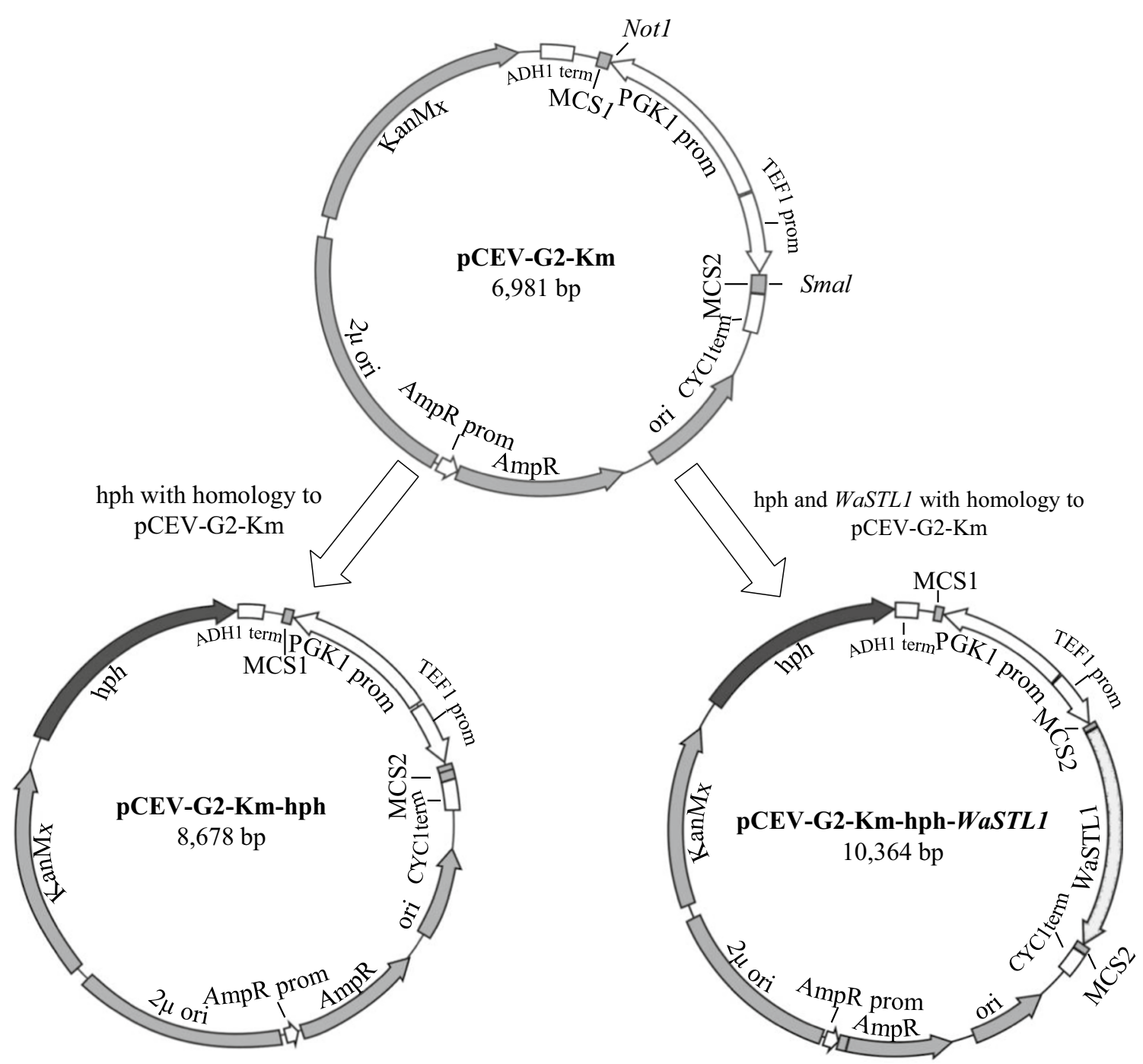

Fig. 1 A diagram illustrating the plasmid construction. hph stands for hygromycin-B-phosphotransferase protein conferring resistance to hygromycin, whereas KanMx stands for kanamycin resistance

concentrative nature of the transporter was confirmed by measuring the radiolabeled glycerol accumulation ratio as previously described [29]. A single concentration of $500 \mathrm{mM}\left[{ }^{14} \mathrm{C}\right]$ glycerol with an SA of $2000 \mathrm{GBq} \cdot \mathrm{mol}^{-1}$ was used. The generally accepted value for intracellular volumes in yeasts $\left[2 \mu \mathrm{L} \cdot \mathrm{mg}^{-1} \mathrm{dry}\right.$ weight] was assumed to estimate the therein glycerol intracellular molarity. The same concentration of CCCP as above was used to counteract the Stl1-driven glycerol accumulation, causing the efflux of nonmetabolized glycerol from the cell. Radioactivity was measured in a Beckman LS6000 scintillation counter.

\section{Statistical analysis and reproducibility}

An analysis of variance (ANOVA), Tukey's test, $t$ test, linear regression, and nonlinear fit of Michaelis-Menten kinetic curves were performed using Prism 6.01 software (GraphPad Software, La Jolla, CA, USA). Results were considered statistically significant when $p<0.05$. The results of glycerol transport and consumption, growth in liquid media, and RTqPCR derived from at least two independent assays, each one performed in duplicate.

\section{Results and discussion}

\section{Assessment of W. anomalus as a glycerol-metabolizing strain}

Wickerhamomyces anomalus strain LCBM1105 (formerly Pichiaanomala, Hansenula anomala and Candida pelliculosa) was isolated from the Brazilian cachaça wort and 
identified in a previous survey as an excellent glycerol consumer that is able to grow on solid YP with up to $25 \%$ glycerol [9]. In this study, growth on liquid YP or YNB with increasing glycerol concentrations up to $10 \%$ was assessed. Specific growth rates were statistically invariant $\left(0.2 \mathrm{~h}^{-1}\right)$ on YNB and YP up to $5 \%$ glycerol. The highest $\mu_{\mathrm{g}}$ of $0.28 \mathrm{~h}^{-1}$ was obtained in YP with $10 \%$ glycerol (Fig. 2a). This is compatible with the supposedly osmophilic nature of $W$. anomalus [16]. S. cerevisiae wild-type (WT) BY4741 under the same conditions grew much slower: $\mu_{\mathrm{g}}= \pm 0.1 \mathrm{~h}^{-1}$ in either YNB or YP. S. cerevisiae is known to be an extremely poor
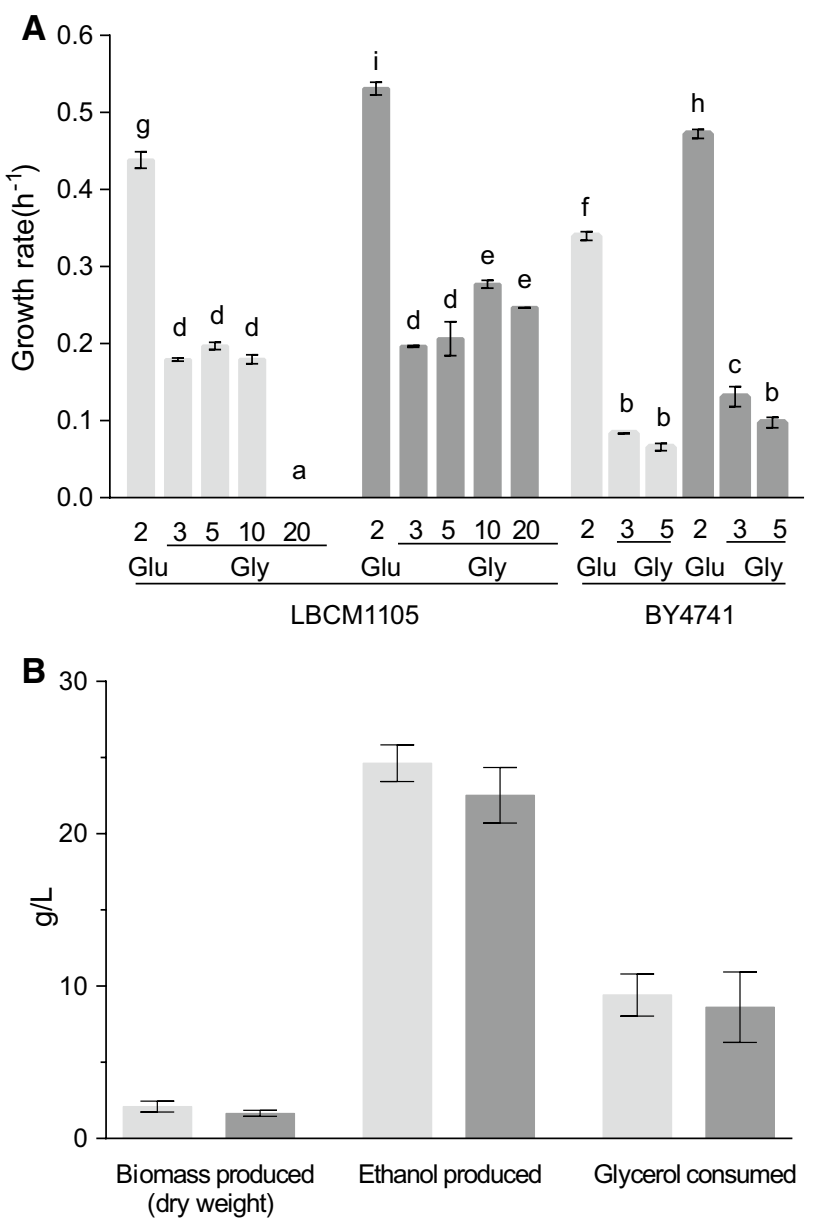

Fig. 2 Growth of W. anomalus LBCM1105 and S. cerevisiae BY4741 on glycerol. a Batch cultures with an air/liquid ratio of 5:1 and different concentrations of glycerol $(\% \mathrm{w} / \mathrm{v})$ were used to estimate the specific growth rate during the log phase. Controls in $2 \%$ glucose are also presented. Cells were grown in YNB (light-gray bars) or YP (dark-gray bars).The results represent the average and standard deviation of at least two independent assays. Different letters represent a statistically significant difference with $p<0.05$ (Tukey's test). BY4741 was not able to grow in $10 \%$ glycerol. (B) Biomass and ethanol production and glycerol consumption after $72 \mathrm{~h}$ of culture in YP with 3\% glycerol (light-gray bars) or YP with 5\% glycerol (darkgray bars). The results represent the average and standard deviation of at least two independent assays. There was no statistical difference between the results obtained in each medium grower on YNB glycerol, demanding nitrogen-rich supplements like peptone or glutamic acid [39]. Some strains do not grow on glycerol at all. The most recurrent reason pointed out in the literature for this inability is $\operatorname{NAD}(\mathrm{H})$ redox imbalance, caused at the level of glycerol 3P shuttle between the cytosol and the mitochondria (Gpd1/Gut $2_{\text {mit }}$ ) [31]. In S. cerevisiae, the operational glycerol assimilation pathway involves the glycerol permease Stl1, the glycerol kinase Gut1, and the glycerol 3P shuttle inner mitochondrial membrane glycerol 3P dehydrogenase Gut $2{ }_{\text {mit }}$ [43]. Nevertheless, there is no consensus regarding the causes underlying the difference between $S$. cerevisiae and other yeast species that, otherwise, can grow well on glycerol. Attempts to randomly evolve nonuser strains into users were accomplished, but they were often unstable and easily reverted [39, $45,67]$. Reciprocal hemizygosity analysis between a bad and a good glycerol consumer suggested that only Gut1 activity governs the glycerol growth ability [65]. Surprisingly, in another study using the same method, two apparently glycerol-unrelated loci were found to improve the yeast's ability to grow on glycerol, the SSK1 encoding an osmoregulation signaling effector, and $U B R 2$ encoding a component of the ubiquitin ligase complex [64]. Why and how these proteins are able to promote growth on glycerol are presently unknown, and neither SSK1- or UBR2-like genomic sequences could be found in the $W$. anomalus genome [53, 57]. These authors further expressed in $S$. cerevisiae an allele from the glycerol channel FPS1 originating from a good glycerol-consuming yeast [64], obtaining a maximum $\mu_{\mathrm{g}}$ on glycerol in a minimal medium of $\pm 0.1 \mathrm{~h}^{-1} \mu_{\mathrm{g}}$ of the best yeast glycerol growers, assessed in YNB 2\% glycerol [30], was generally at least $2.5 \times$ higher, and specifically that of W. anomalus (PYCC4121) was $0.29 \mathrm{~h}^{-1}$, identical to $\mu_{\mathrm{g}}$ obtained in the present work in YP 10\% glycerol.

In the present work, yeasts were cultivated at $30{ }^{\circ} \mathrm{C}$. This temperature was chosen in view of the environmental conditions of the origin of the W. anomalus strain LBMC1105 [9]. Nevertheless, W. anomalus apparently prefers lower temperatures [30]. Survival for 4 weeks on a malt extract medium of one strain has been reported to be best at $10{ }^{\circ} \mathrm{C}$ [38]. Noticeably, glycerol is used by yeast cells for many purposes, including high-temperature stress resistance [59, 73]. It is, therefore, not uncalled for that glycerol utilization at higher temperatures might yield less biomass and a slower $\mu_{\mathrm{g}}$, because the cell needs to maintain proper intracellular glycerol levels $[59,73]$. In S. cerevisiae, this response concomitantly promotes the alleviation of glucose repression over the glycerol permease gene STL1 [14].

The production of biomass (dry weight) and the corresponding amount of glycerol consumed were quantified in W. anomalus cultured on YP with 3 and $5 \%$ glycerol (Fig. 2b). The values were statistically identical $(p<0.05)$ according to the $t$ test under both conditions; at 5\% glycerol, 
a large amount of substrate was left unconsumed (2.8\%). This suggests that, although da Conceição et al. [9]. showed that $W$. anomalus LCBM1105 is able to grow well on solid media with different glycerol concentrations ranging from 2 to $25 \%$, on a liquid medium, the efficiency of glycerol utilization is mostly lost above $3 \%$. In addition, the chromatographic analysis of growth media revealed the presence of ethanol (Fig. 2b). Identically to the biomass produced and glycerol consumed, the ethanol produced was no different in 3 or $5 \%$ glycerol ( $t$ test, $p<0.05$ ). Considering the theoretical conversion of glycerol to ethanol $\left(\mathrm{C}_{3} \mathrm{H}_{6} \mathrm{O}_{3} \rightarrow \mathrm{C}_{2} \mathrm{H}_{5} \mathrm{OH}+\mathrm{CO}_{2}\right)$, only a very small fraction of glycerol was probably used to produce ethanol, around $8.5 \%$ of the total glycerol consumed. Therefore, glycerol fermentation occurs but appears to be residual.

Glycerol can be anaerobically fermented by several bacterial species, producing ethanol, other alcohols, formate, or polyols [8]. Yeasts are, otherwise, able to utilize glycerol as a carbon source only aerobically [4]. Glycerol consumption in S. cerevisiae occurs through the intermediate glycerol 3 -phosphate and supplies mitochondria with reduced $\mathrm{FADH}_{2}$ derived from the activity of Gut $2_{\text {mit }}$, part of the abovementioned shuttle that couples the cytosolic and mitochondrial redox pools [31]. W. anomalus, unlike $S$. cerevisiae, is a Crabtree-negative yeast; therefore, it is incapable of aerobic fermentation of glucose [69]. It shares with other yeasts of the cyanide-resistant respiration (CRR) chain that does not have complexes III and IV and is, therefore, resistant to antimycin-A and cyanide [69]. An alternative cyanideinsensitive ubiquinol oxidase, Aox, already identified in $W$. anomalus [56] performs $\mathrm{O}_{2}$ fixation [55]. The operation of this alternative respiratory chain has been suggested to generate a weaker p.m.f. and therein lower ATP production. In $W$. anomalus, glucose represses both the metabolic flux through this alternative pathway [40] and the expression of $A O X$ [56]. Accordingly, growth on glycerol should allows the alleviation of repression over $A O X$, promoting the functioning of the CRR. There is no information available as to whether $W$. anomalus shares with $S$. cerevisiae the same steps of glycerol assimilation. That being said, the function of Gut 2 would be important to supply mitochondria with $\mathrm{FADH}_{2}$ needed for the function of complex II, this way contributing to increasing the efficiency of respiration in comparison to glucose utilization. Moreover, although, in plants, it has been suggested that CRR promotes the dissipation of unchanneled redox potential as heat [42], in yeasts, there is no evidence supporting that hypothesis. Instead, the present work's finding of ethanol in W. anomalus glycerol cultures suggests that the NADH surplus generated by CRR could be reoxidized by producing ethanol. The residual nature of the putative glycerol/ethanol conversion suggested above is consistent with this possibility. Moreover, the expression of an alcohol dehydrogenase [11] could be rate-limiting the amount of glycerol that can be consumed, causing a halt of glycerol consumption at $\geq 3 \%$ as described above. Any attempt to improve $W$. anomalus glycerol consumption for biotechnological purposes will need to take this into consideration.

\section{Identification and sequencing of WaSTL1}

The good performance of $W$. anomalus on glycerol could, at least in part, derive from the efficiency of the systems ensuring glycerol supply to the cell. An active permease operating as a glycerol $/ \mathrm{H}^{+}$symporter was primordially described in $S$. cerevisiae $[29,48]$ and the gene identified as STL1 [15], a member of the HXT superfamily. Subsequently, this permease was also characterized in C. albicans [24], Debaryomyces hansenii [51], and Zygosaccharomyces rouxii [13]. Other yeast species whose genome has been sequenced display STL1-like sequences (NCBI Database), although the corresponding protein function has not been confirmed. Stl1 proteins share a high degree of identity, with large parts of the amino acid sequence being conserved. The alignment of Stl1 from S. cerevisiae S288c (AJV19167), C. albicans WO-1 (EEQ 46634), Millerozyma M. farinosa CBS7064 (CCE85634), and Scheffer somyces S. stipitis CBS6054 (XP_001383774) was used to design degenerate primers covering, on the basis of $S$. cerevisiae, the region between the 43rd and the 478th amino acid (Fig. 3). The resulting $W$. anomalus amplicon of $1287 \mathrm{bp}$ was sequenced and observed to align with the genome available at CTBE (Bioethanol Science and Technology National Lab., Campinas SP, Brazil) [53, 57], allowing the identification of a putative ORF with $1686 \mathrm{bp}$. Nucleotide BLAST analysis of this DNA sequence revealed $99 \%$ identity with a hypothetical ORF XM_019185120 from W. anomalus strain NRRL Y-366-8, and 87\% identity with the STL1 from W. ciferrii (CCH43320). Both genes putatively encode proteins that are considered members of the sugar transporters superfamily like $S$. cerevisiae Stl1. In silico translation of the W. anomalus LCBM1105 amplicon yielded a sequence of 561 amino acid residues with the highest identity and similarity to $C$. albicans St11 [72\% identity (372/520) and 84\% similarity (441/520)], followed by S. stipitis [71\% identity (371/524) and $83 \%$ similarity (438/524)] and S. cerevisiae [61\% identity (317/521) and 77\% similarity (403/521)]. The alignment of these four Stl1 proteins clearly shows a high degree of conservation (Fig. 3). The Stl1 referred to above from $Z$. rouxii (CAR30743), D. hansenii CBS767 (CAG85514), and $M$. farinosa shares with WaStl1 an increasingly less identity, 58,40 , and $39 \%$, respectively.

WaStl1 was subsequently analyzed in silico. In general, transporters like Stl1 display 10-12 hydrophobic $\alpha$-helix domains that should correspond in vivo to transmembrane domains (TMDs) of the protein [54]. Several servers were 
SCSTL1

WaSTL1

CaSTL1

SSSTL1

SCSTL1

WaSTL1

CaSTL1

SSSTL1

SCSTL1

WaSTL1

CaSTL1

SSSTL1

SCSTL1

WaSTL1

CaSTL1

SSSTL1

SCSTL1

WaSTL1

CaSTL1

SSSTL1

SCSTL1

WaSTL1

CaSTL1

SSSTL1

SCSTL1

WaSTL1

CaSTL1

SSSTL1

SCSTL1

WaSTL1

CaSTL1

SSSTL1

SCSTL1

WaSTL1

CaSTL1

SSSTL1

SCSTL1

WaSTL1

CaSTL1

SSSTL1
MKDLKLSNFKGKFISRTSHWGLTGKKLRYFITIASMTGFSLFGYDQGLMASLITGKQFNY -----MG-FDW-KSRTNTSGLSGRALRVSVTLTATLGFSLFGYDQGLMSGLITGHEFNY ----MGGFIDNIFKRTTTAGLTGRKLRAAVTITATLGFSLFGYDQGLMAGLISAEQFNW -----MAYLDWLTARTNTFGLRGKKLRAFITVVAVTGFSLFGYDQGLMSGIITADQFNS

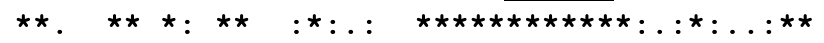

EFPATKENGDHDRHATVVQGATTSCYELGCFAGSLFVMFCGERIGRKPLILMGSVITIIG EFPATKGN-------SVNQGAVTACYEIGCFFGALFAMFRGERIGRRPLIILGAFIIIIG EFPATKDN------SVIQGAVTASYELGCFFGAIFALLRGDALGRKPIIFFGATIIILG EFPATRNN------STIQGAVTSCYELGCFFGAVFALLRGERIGRRPLVLCGSLIIILG

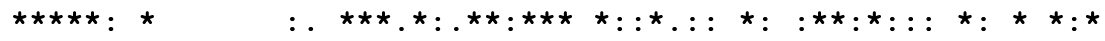

AVISTCAFRGYWALGQFI IGRVVTGVGTGLNTSTIPVWQSEMSKAENRGLLVNLEGSTIA TLISVTAYRDDWGTGQFVVGRVITGIGNGMNTATIPVWQSEMSKPEKRGMLVNLEGSVVA TIISVTPFRPHWPLGQFVVGRVITGIGNGMNTATIPVWQSEMSKPENRGKLVNLEGAVVA TVISVTAFHPHWSLGQFVIGRVITGIGNGMNTAT IPVWQSEMSRAENRGRLVNLEGSVVA

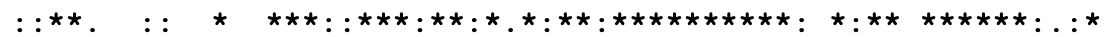

FGTMIAYWIDFGFSYTNSSVQWRFPVSMQIVFALFLLAFMIKLPESPRWLISQSRTEEAR IGTFVAYWVDFGMSYVNNSSQWRFPVAFQIFFAFFVMIGALQLPESPRWLLSKGRREEAV FGTFIAYWLDFGLSYVDSSVSWRFPVAFQIFFALWVIFGI IQLPESPRWLISKDRKPEAF VGTCIAYWLDFGLSYVDNSVSWRFPVAFQIVFASVLFVGMLQLPDSPRWLVANHRRAEAL

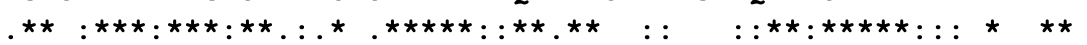

YLVGTLDDADPNDEEVITEVAMLHDAVNRTKHEKHSLSSLFSRGRSQNLQRALIAASTQF FVLAALNDVPIDDEGVDEEATAIQDAVEKVSKKQISIKEVFTGGKTQHFRRMLIGSSTQF EVLAALNDTTPDDDAIVAEASVIIDAVRRNAKVQAGFKDLFTGGKTAHFQRMLIGSSTQF QVLSALKDLPEDDEEILNEAEVIQESVDKFA-GHASVKEVFTGGKTQHWQRMVIGSSTQF

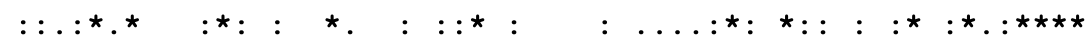

FQQFTGCNAAIYYSTVLFNKTIKL--DYRLSMI IGGVFATIYALSTIGSFFLIEKLGRRK FQQFTGCNAAIYYSTVLFEQTIGL--TGKLPLILGGVFATIYALSTIPSFFLIEKLGRRN FQQFTGCNAAIYYSTLLFYETVFHHTKYRLSMILGGVFATIYALATLPSFFLIDTLGRRN FQQFTGCNAAIYYSTVLFQDTIGL--ERRMALI IGGVFATVYAIFTIPSFFLVDTLGRRN

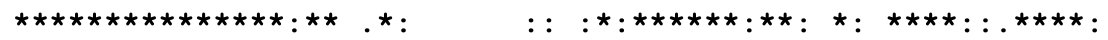

LFLLGATGQAVSFTITFACLVKENKENARGAAVGLFLFITFFGLSLLSLPWIYPPEIASM LFLIGATGQGCSFIITFGCLVKDTTQNAKGAAVGLFLFIVFFAFTILPLPWVYPPEINPL LFLIGAIGQGISFLISFACLINPTEQNAKGAAVGIYLFIVFFAFTILPLPWIYPPEINPL LFLIGAMGQGIAFTITFACLIDDTENNAKGAAVGLFLFICFFAFTILPLPWVYPPEINPL

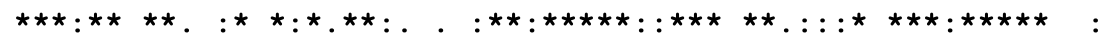

KVRASTNAFSTCTNWLCNFAVVMFTPIFIGQSGWGCYLFFAVMNYLYIPVIFFFYPETAG RTRTVASAISTCTNWLTNFAVVMFTPVFIANARWGCYLFFAVMNFIFVPIIFFFY PETAG RTRTTASAVSTCTNWLTNFAVVMFTPPFISASGWGCYLYFAVMNFLFVPIIFFFYPETAG RTRTIASAISTCTNWICNFAVVMFTPVFVTNTRWGAYLFFAVMNFLFVPIIFFFY PETAG

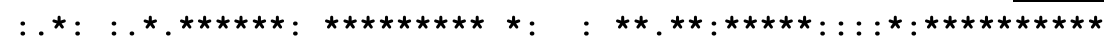

RSLEEIDIIFAKAYEDGTQPWRVANHLPKLSLQEVEDHANALGSYDDEM-EKEDFGEDRV RSLEEMDIMFAKAHVEKKPVWRVAQTMPKMNHREVERAAVELGLFDEIEFQNDGFDDKAS RSLEEIDI IFAKAYVEKRQPWRVAATLPKLSLQEVEDESKSLGLYDDD-FEKDNFETKED RSLEEIDIIFAKAFVDKRQPWRVAATMPKLSNHEIEDEANRLGLFDDGTFDKEAFETKEN

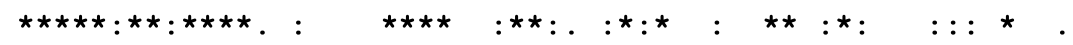

EDTYNQINGDNSSS-SSNIKNEDTVNDKANEEG---------

A-----SIPDAEKEGTSGTDTPDSQENNNNHSGLFVKKGDDNV

I-----SDGTASNS----------------NGVFEKPENV--

A-----SSSS-------------------------------- 
4Fig. 3 WaStl1 amino acid sequence alignment. W. anomalus LBCM1105-WaSTL1 (AKU75155.2) was reverse-translated in silico and aligned against with the Stl1 proteins from $S$. cerevisiae S288CScSTL1 (AJV19167.1), C. albicans WO-1-CaSTL1 (EEQ 46634.1), and S. stipitis CBS6054-SsSTL1 (XP_001383774). Alignment was performed at https://pir.georgetown.edu/pirwww/search/multialn. shtml using ClustalWat its default settings. The underlined amino acids are the positions corresponding to the FW- and Rv-degenerated primers

used (see "Materials and methods"), all of which predicted, identically to $S c S t 11$, that the protein locates at the plasma membrane and that it has 11 or 12 TMDs. Hence, the sequence identity, the hydropathy profile analysis, and the predicted subcellular location strongly suggest that the $W$. anomalus amplicon corresponds to an S. cerevisiae Stl1 ortholog. The probability of orthology was estimated using eggNOG 4.5 [22], and it was very high for the pairs WaStl1/ScStl1 $\left(e\right.$ value $\left.=1.18 \times 10^{-260}\right)$, WaStl1/S. stipitis Stl1 $\left(e\right.$ value $\left.=1.25 \times 10^{-293}\right)$, and WaSt11/Yarrowia lipolytica Stl1p $\left(e\right.$ value $=e$ value $\left.1.9 \times 10^{-245}\right)$. The WaSTL1 genomic sequence was recorded at GenBank under the accession number KP856970.2, as well as in the Transporter Classification Database (TCDB) under the number 2.A.1.1.137. The latter included WaSTL1 in the Major Facilitator Superfamily (2.A.1); that is, in the group of electrochemical potential-driven symporters. The following results confirm the appropriateness of this inclusion.

\section{Complementing S. cerevisiae $\Delta$ st/1 with WaSTL1}

STL1 from W. anomalus was expressed in S. cerevisiae (BY4741 $\Delta s t l 1$ ). This should provide evidence on the function of permease in a heterologous environment, while simultaneously improving S. cerevisiae's glycerol consumption ability through improved uptake in the recipient yeast. To accomplish this, specific primers designed to amplify the WaSTL1 complete ORF and hph cassette (Table 2) were used to obtain two amplicons that were inserted in the pCev-G2-Km (Table 1, Fig. 1), and WaSTL1 was inserted in frame with the TEF1 strong promoter. The construction (pCevWaSTL1) was verified by PCR amplification, digestion, and sequencing. After confirmation, the plasmid was used to transform S. cerevisiae $\Delta$ stll (Table 1). Growth on glycerol should provide a rough indirect assessment of the heterologous expression of the glycerol transporter. Therefore, transformants and controls (untransformed S. cerevisiae and W. anomalus WT strains) were grown on YNB with $5 \%$ glycerol (reagent-grade) as the sole carbon and energy source (Fig. 4). Antibiotic resistance was kept to ensure plasmid maintenance. Results show, as expected [9], that $W$. anomalus grows better than $S$. cerevisiae [15], although the strain used in the present work, BY4741, is different from the ones assessed before in that regard. On the other hand, the $S$. cerevisiae $\Delta$ stll mutant, alone or harboring an empty plasmid, did not grow on glycerol, whereas the transformant recovered the ability to grow on glycerol, although it took longer to resume growth. This suggests that the construction ensures the appropriate expression of the gene. To verify this, all these strains/conditions were used to quantify STL1 expression by RT-qPCR using $A C T 1$ as a reference gene. In all cases, cells were collected in the log phase. The results (Fig. 5) show that, in W. anomalus, as reported for S. cerevisiae [15], glucose exerts a repressive effect over the expression of STL1, whereas glycerol acts as an inducer. Moreover, according to the results from growth on glycerol observed in liquid media (Fig. 4), the expression of STL1 in W. anomalus is almost twice that in $S$. cerevisiae, suggesting a crucial role of the transporter in supplying a metabolic flux. The expression of WaSTL1 in S. cerevisiae $\Delta$ stll appears to be slightly lower than in identically cultivated WT $S$. cerevisiae, but these results were actually not statistically different. The higher affinity of the WaStl1 compared to ScStl1 was, therefore, not enough per se to ensure a significantly better growth of the recipient $S$. cerevisiae on glycerol.

\section{WaStl1 glycerol transport}

To characterize the mechanism of WaStl1-mediated glycerol transport, radiolabeled glycerol uptake was quantified using the well-established methodologies [29, 48]. In all yeasts where Stl1 was studied in detail, this transporter was shown to operate as an $\mathrm{H}^{+}$symporter, a saturable active permease. Simultaneously, glycerol can permeate through the Fps1 channel. Therefore, glycerol uptake kinetics present two branches: one corresponding to the saturable, enzyme-like active transport and the other to the nonsaturable passive diffusion of glycerol through the open channel, following a full equation corresponding to $V=V_{\max } \cdot[\mathrm{S}] /\left(K_{\mathrm{m}}+[S]\right)+K_{\mathrm{d}} \cdot[S]$ [48]. As shown above, the $S$. cerevisiae WT and transformed strains were grown on YNB with 5\% glycerol. To promote the growth of the deleted strain, $0.3 \%$ glucose was added. Cultures were collected in the log phase and used to assay the initial uptake rates of radiolabeled glycerol (Fig. 6). The data from the WT and transformant strains followed the full equation, whereas the $S$. cerevisiae $\Delta$ stll mutant strain presented only the second component of linear diffusion as expected. The estimated value of the corresponding $K_{\mathrm{d}}$ constant was $0.0043 \pm 0.0001 \mathrm{~L} \cdot \mathrm{h}^{-1} \cdot \mathrm{g}^{-1}(p<0.0001)$, a value similar to the previously reported one with the other genetic backgrounds [15, 29]. This was used to iterate the data from the strains displaying the full equation, allowing the calculation of the kinetic constants of the active transport component. The $S$. cerevisiae WT strain presented $K_{\mathrm{m}}$ of $2.26 \pm 0.22 \mathrm{mM}$, slightly higher than the previously determined value in different $S$. cerevisiae genetic backgrounds [15, 29], and $V_{\max }$ of $527.4 \pm 25.91 \mu \mathrm{mol} \cdot \mathrm{h}^{-1} \cdot \mathrm{g}^{-1}$ 


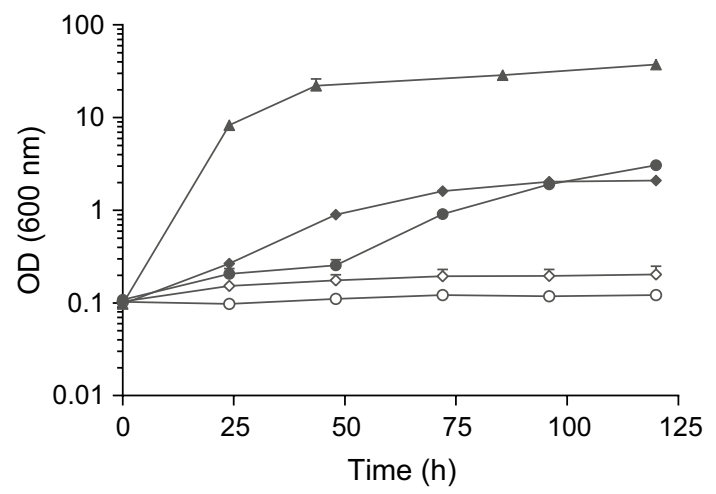

Fig. 4 Ability of the recombinant yeasts to grow on glycerol. Cultures of $S$. cerevisiae BY4741 WT (filled circle), $\Delta$ stll (open circle), $\Delta$ stll pCevhph (open diamond), $\Delta$ stll pCevWaSTL1 (filled diamond), and $W$. anomalus LBCM1105 (filled triangle) in YNB with 5\% glycerol. The results represent the average and standard deviation of two independent experiments performed in duplicate. The bars represent the standard deviation of the mean

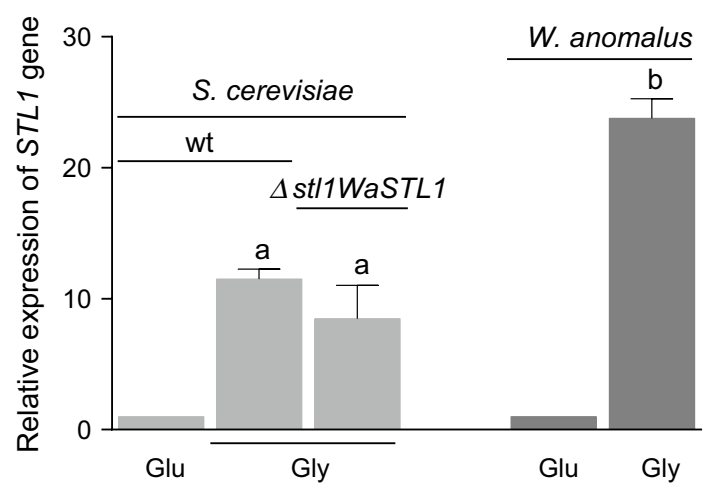

Fig. 5 Quantification of STL1 mRNA by RT-qPCR. Results of the expression of STL1 on S. cerevisiae BY4741 WT cultivated on 2\% glucose or 5\% glycerol, as well as $\Delta$ stl1 harboring pCevWaSTL1 cultivated on 5\% glycerol (gray bars), and on W. anomalus LBCM1105 (dark bars), grown on $2 \%$ glucose or $5 \%$ glycerol. Cells were collected in the mid-log phase. RT-qPCR was performed using ACT1 as an expression reference. The results represent the average and standard deviation of at least two independent assays. Different letters represent a statistically significant difference with $p<0.05$ (Tukey's test)

$\left(r^{2}=0.9801\right)$. WaStl1-mediated transport in the recombinant strain presented more than twice the affinity, with $K_{\mathrm{m}}$ of $0.96 \pm 0.15 \mathrm{mM}$, but a much lower $V_{\max }$ of $148.3 \pm 10.16$ $\mu \mathrm{mol} \cdot \mathrm{h}^{-1} \cdot \mathrm{g}^{-1}\left(r^{2}=0.9224\right)$. This is consistent with using a plasmid expression, even under a $T E F 1$ promoter, which was recently found to be able to induce a high expression in glycerol synthetic media [20]. The lower $V_{\max }$ from the transformant is consistent with the lower STL1 mRNA (Fig. 5), although the corresponding values could not be considered statistically different.

CCCP is a well-known ionophore that acts as an uncoupler, affecting the activity of the secondary transporters

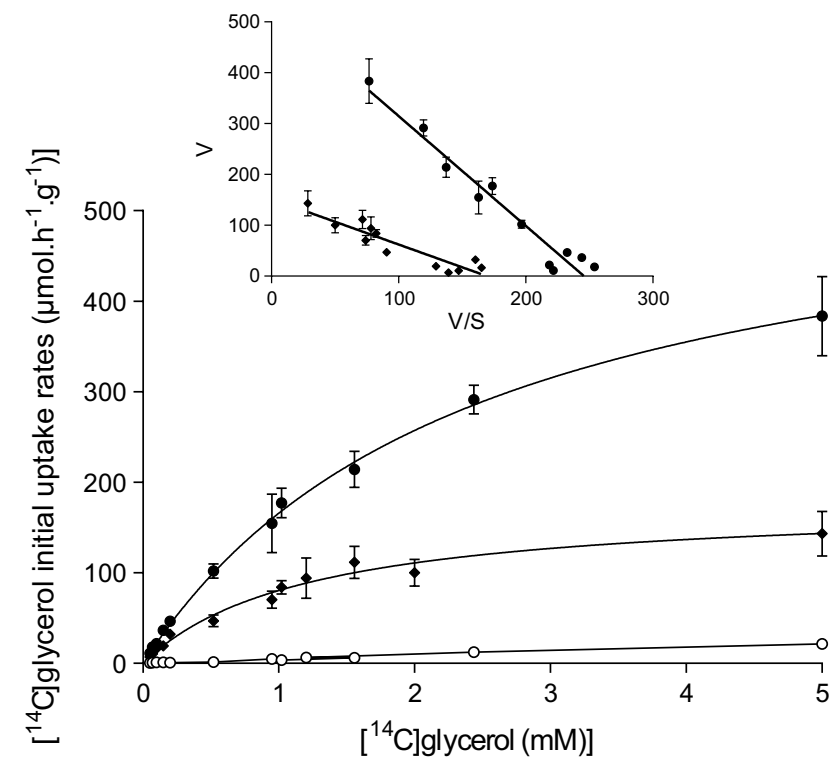

Fig. 6 Kinetics of glycerol transport. A Michaelis-Menten plot of $\left[{ }^{14} \mathrm{C}\right]$ glycerol's initial uptake rates by BY4741 WT (filled circle) and $\Delta s t l 1$ pCevWaSTL1 (filled diamond) cultivated in YNB with $5 \%$ glycerol and $\Delta s t l 1$ (open circle) cultivated in YNB with 5\% glycerol, with $0.3 \%$ glucose added. The results represent the mean of transport obtained from two independent experiments performed in duplicate. They also represent the average and standard deviation of at least two independent assays. Inset: Eadie-Hofstee plot of the same results, except for the BY4741 $\Delta$ stl

depending on $\Delta \mathrm{pH}$ and/or $\Delta \Psi$, as is the case of $\mathrm{H}^{+}$symporters like $S c$ Stl1. Bearing in mind that this drug previously proved effective in eliminating the uptake of glycerol by $S c$ Stl1 [15], CCCP was used to test WaStl1-mediated glycerol transport. A single concentration of CCCP was used $[15,18]$ against three radiolabeled glycerol concentrations around the $K_{\mathrm{m}}$ values mentioned above: $0.2,2$, and $5 \mathrm{mM}$. The initial uptake rates were determined in the absence and in the presence of CCCP (Fig. 7). As expected, the drug had no effect on the uptake of glycerol by the $\Delta$ stll mutant. Since this strain does not express the transporter, the remaining glycerol entry should occur through the open Fps1 glycerol channel, which should not be affected by the action of uncouplers. In the other two strains, CCCP significantly decreased glycerol uptake, leaving an almost identical residual glycerol entry, again possibly occurring through Fps1 [48]. This confirms that WaStl1 operates in the dependence of the p.m.f. most probably as an $\mathrm{H}^{+}$symporter like $S c \mathrm{Stl1}$ $[15,30,48]$. Accordingly, the accumulative nature of $\mathrm{WaStl} 1$ was assessed by quantifying the Stl1-driven glycerol in/out accumulation ratio. This was performed in glycerol and glucose-grown cells under identical physiological conditions (Fig. 8). The maximum accumulation ratio of glycerol on glycerol-grown $W$. anomalus was approximately $15 \times$, well above the chemical equilibrium, indicating concentrative 

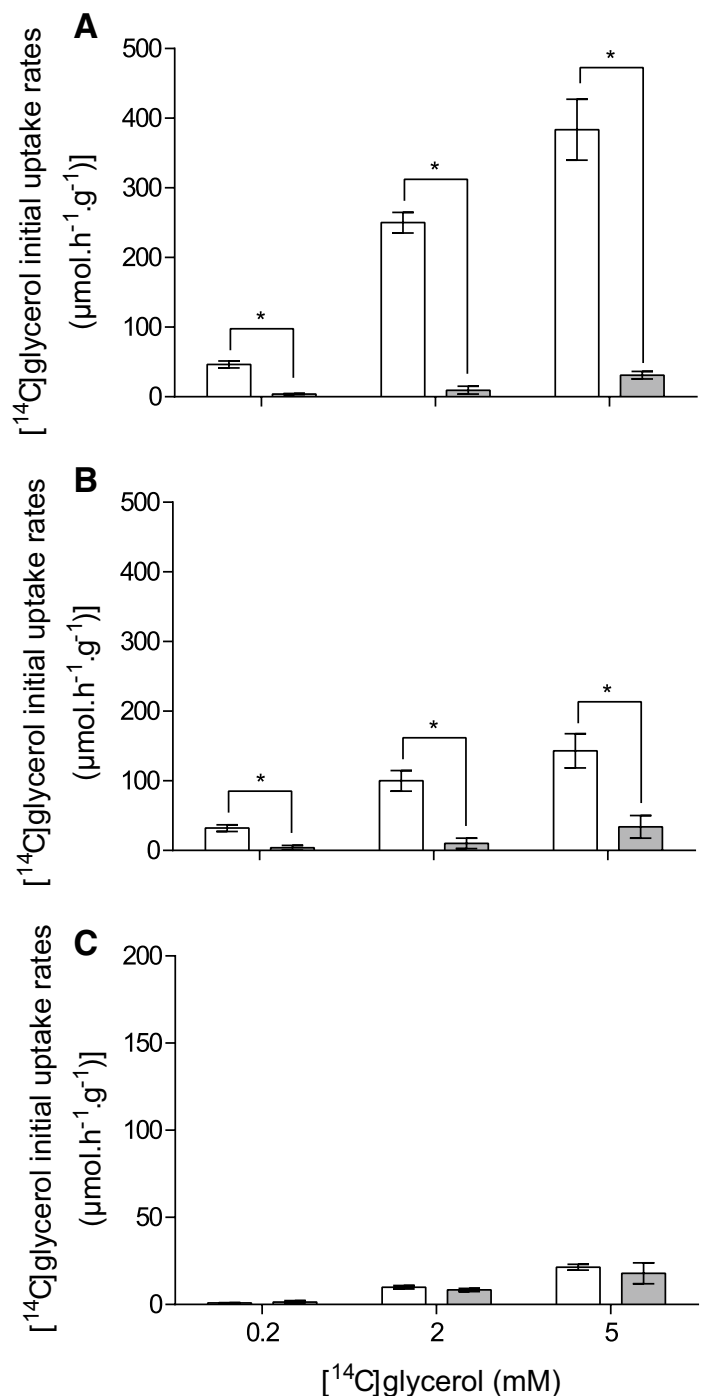

Fig. 7 Prevention of glycerol transport by the ionophore CCCP. Transport of $\left[{ }^{14} \mathrm{C}\right]$ glycerol $(0.2,2$, and $5 \mathrm{mM})$ in the absence (blank bars) and in the presence (gray bars) of CCCP, by BY4741 WT (a) and $\Delta$ stll pCevWaSTL1 (b) cultivated in YNB with 5\% glycerol and $\Delta s t l 1$ (c) cultivated in YNB with $5 \%$ glycerol and $0.3 \%$ glucose. ${ }^{*}$ Statistically significant difference with $p<0.05$ between transport with (w/) and without (w/o) CCCP

uptake. In WT S. cerevisiae, the in/out glycerol ratio (as $V_{\max }$ ) varied significantly depending on the strain in use [29, 48], indicating large differences in the regulation of expression. As expected, CCCP induced an efflux of nonmetabolized intracellular radiolabeled glycerol consistent with the dissipation of the accumulation ratio by the elimination of the driving p.m.f. On the other hand, the same strain cultivated on glucose presented an in/out glycerol accumulation ratio very close to equilibrium, compatible with the transport visible on glycerol-grown cells being repressed by glucose. These results suggest that, in W. anomalus, as in S. cerevisiae, not only does the STL1 gene encode a concentrative

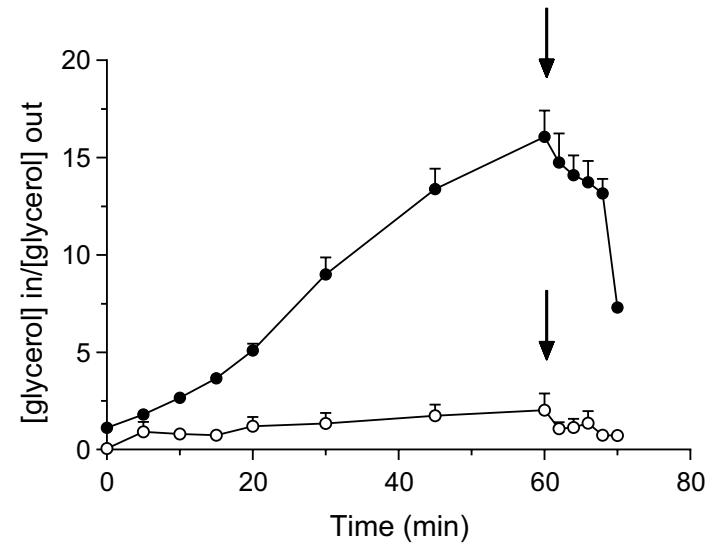

Fig. 8 Stl1-mediated glycerol accumulation. Radiolabeled glycerol int/out ratio on $W$. anomalus grown on YP with $2 \%$ glycerol (filled circle) or glucose (open circle). The arrow indicates the time point of addition of the uncoupler ionophore CCCP

secondary transporter of glycerol dependent on p.m.f., but also it is under glucose repression and is induced by growth on glycerol, as also shown by RT-qPCR quantification of STL1 expression (Fig. 5). Importantly, the affinity of $W$. anomalus Stl1 permease is higher than the one determined in $S$. cerevisiae in both strains used previously $[15,29]$ and the BY4741 used now. All of these features confirm the better growth on glycerol observed in W. anomalus.

\section{Conclusions}

The $W$. anomalus strain LBCM1105 that was used in this work was previously noticed to have a remarkable ability to grow on glycerol and to use it as a sole carbon and energy source [9]. Among other possibilities, this should be achieved with the contribution of an efficient glycerol transport, able to fuel fast metabolism. The present work was aimed at identifying and characterizing the associated glycerol transporter. The genome of $W$. anomalus was primordially only partially sequenced and no STL1like sequence was available; therefore, we used a degenerate primer-based strategy that allowed the retrieval of the full ORF. This was found to be quite similar to DNA sequences from other yeast species presumably encoding Stl1 proteins. Moreover, the putative WaStl1 protein has 561 amino acids and 11 or 12 putative transmembrane helices, and probably locates at the plasma membrane, all of which consistent with a transporter. The aminoacid sequences showed a high degree of conservation with the numerous Stl1-like proteins available in databases, most of which named exclusively on the basis of amino acid sequence homology. The Stl1 proteins that were actually studied, from S. cerevisiae [15], C. albicans [24], Z. 
rouxii [13], and D. hansenii [18, 51], all function as highaffinity, concentrative glycerol-specific permeases of the $\mathrm{H}^{+}$symport type, consequently in the dependence of a functional p.m.f. The present results show that this is also the case for $W$. anomalus Stl1. The gene was successfully cloned and expressed in S. cerevisiae, complementing the $\Delta s t l 1$ mutant phenotype on glycerol. Moreover, WaStl1 displayed saturation kinetics with twice the affinity of $S c$ Stl1, as well as sustained glycerol intracellular accumulation against the chemical gradient in the dependence of p.m.f. As reported for S. cerevisiae, the results of STL1 mRNA quantification by RT-qPCR, as well as by radiolabeled glycerol kinetics and accumulation, showed that WaSTL1 is under glucose repression and is highly induced by growth on glycerol. Importantly, STL1 mRNA was also much higher in $W$. anomalus than in WT $S$. cerevisiae. The better growth of $W$. anomalus on glycerol compared to $S$. cerevisiae could, therefore, derive at least in part from a combination of Stl1 higher affinity with more proteins. Importantly, another cause for the better performance of $W$. anomalus is apparently related to the production of residual amounts of ethanol and the derepression of $A O X$ from the CRR. Channeling glycerol through the glycerol $3 \mathrm{P}$ shuttle fuels mitochondria with $\mathrm{FADH}_{2}$, whereas producing ethanol by a glycerol-derepressed ethanol dehydrogenase could compensate for the CRR-generated NADH excess. The present work paved the way for a better understanding of the metabolism of $W$. anomalus, as an important non-Saccharomyces biotechnological tool, as well as the possibility of optimizing its growth on glycerol wastes for industrial applications.

Acknowledgements This work was supported by grants from Fundação de Capacitação de Pessoal de Nível Superior from the Ministry of Education-CAPES/Brazil (PNPD 2755/2011; PCF-PVE 021/2012), from FEDER through POFC-COMPETE and by FCT through strategic funding (UID/BIA/04050/2013), from Universidade Federal de Ouro Preto, and a research fellowship from Conselho Nacional de Desenvolvimento Científico e Tecnológico-CNPq (Brazil) Process 304815/2012 (research grant) and Process 305135/2015-5 (research fellowship to R.L.B.). C.L. is supported by the strategic program UID/BIA/04050/2013 [POCI-01-0145-FEDER-007569] funded by national funds through the FCT I.P. and by the ERDF through the COMPETE2020-Programa Operacional Competitividade e Internacionalização (POCI).The AUXPE-PVES 1801/2012 (Process 23038.015294/2016-18) from Brazilian Government supported a grant of Visiting Professor to C.L. and a research fellowships to A.C.C. and to F.F.O.

\section{Compliance with ethical standards}

Conflict of interest Authors wish to confirm that there are no known conflicts of interest associated with this publication and there has been no significant financial support for this work that could have influenced its outcome.

\section{References}

1. Amaral PFF, Ferreira TF, Fontes GC, Coelho MAZ (2009) Glycerol valorization: new biotechnological routes. Food Bioprod Process 87:179-186. https://doi.org/10.1016/j.fbp.2009.03.008

2. Arous F, Atitallah IB, Nasri M, Mechichi T (2017) A sustainable use of low-cost raw substrates for biodiesel production by the oleaginous yeast Wickerhamomyces anomalus. 3 Biotech 7:268. https://doi.org/10.1007/s13205-017-0903-6

3. Ausubel FM, Struhl K, Smith JA, Seidman JG, Moore DD, Kingston RE, Brent R (1996) Current protocols in molecular biology. Wiley, New York

4. Barnett J, Yarrow D, Payne R, Barnett L (2000) Yeasts: characteristics and identification, 3rd edn. Cambridge University Press, Cambridge. https://doi.org/10.1046/j.1525-1470.2001.18620 20a.x

5. Brasil (2013) Plano Decenal de Expansão de Energia. Brasília, Brasil http://www.epe.gov.br/sites-pt/publicacoes-dados-abert os/publicacoes/PublicacoesArquivos/publicacao-49/topico-86/ Relat\%C3\%B3rio\%20Final\%20do\%20PDE\%202022.pdf

6. Brasil (2016) Lei N. 13.263 - Altera a Lei no 13.033, de 24 de setembro de 2014, para dispor sobre os percentuais de adição de biodiesel ao óleo diesel comercializado no território nacional. Brasília, Brasil http://www2.camara.leg.br/legin/fed/lei/2016/ lei-13263-23-marco-2016-782625-publicacaooriginal-14981 8-pl.html

7. Buchan DW, Minneci F, Nugent TC, Bryson K, Jones DT (2013) Scalable web services for the PSIPRED protein analysis Workbench. Nucleic Acids Res 41:W349-W357. https://doi. org/10.1093/nar/gkt381

8. Clomburg JM, Gonzalez R (2013) Anaerobic fermentation of glycerol: a platform for renewable fuels and chemicals. Trends Biotechnol 31:20-28. https://doi.org/10.1016/j.tibte ch.2012.10.006

9. da Conceicao LE, Saraiva MA, Diniz RH, Oliveira J, Barbosa GD, Alvarez F, Correa LF, Mezadri H, Coutrim MX, Afonso RJ, Lucas C, Castro IM, Brandao RL (2015) Biotechnological potential of yeast isolates from cachaça: the Brazilian spirit. J Ind Microbiol Biotechnol 42:237-246. https://doi.org/10.1007/ s10295-014-1528-y

10. DanielGietz R, Woods RA (2002) Transformation of yeast by lithium acetate/single-stranded carrier DNA/polyethylene glycol method. In: Guthrie C, Fink GR (eds) Methods in enzymology, vol 350. Academic Press, New York, pp 87-96. https://doi. org/10.1016/S0076-6879(02)50957-5

11. De Smidt O, Du Preez JC, Albertyn J (2008) The alcohol dehydrogenases of Saccharomyces cerevisiae: a comprehensive review. FEMS Yeast Res 8:967-978. https://doi.org/10.111 $1 / \mathrm{j} .1567-1364.2008 .00387 . \mathrm{x}$

12. Díaz-Rincón DJ, Duque I, Osorio E, Rodríguez-López A, EspejoMojica A, Parra-Giraldo CM, Poutou-Piñales RA, AlmécigaDíaz CJ, Quevedo-Hidalgo B (2017) Production of recombinant Trichoderma reesei cellobiohydrolase II in a new expression system based on Wickerhamomyces anomalus. Enzyme Res 2017:6980565. https://doi.org/10.1155/2017/6980565

13. Duskova M, Ferreira C, Lucas C, Sychrova H (2015) Two glycerol uptake systems contribute to the high osmotolerance of Zygosaccharomyces rouxii. Mol Microbiol 97:541-559. https ://doi.org/10.1111/mmi.13048

14. Ferreira C, Lucas C (2007) Glucose repression over Saccharomyces cerevisiae glycerol/ $\mathrm{H}^{+}$symporter gene $S T L 1$ is overcome by high temperature. FEBS Lett 581:1923-1927. https://doi. org/10.1016/j.febslet.2007.03.086

15. Ferreira C, van Voorst F, Martins A, Neves L, Oliveira R, Kielland-Brandt MC, Lucas C, Brandt A (2005) A member of the 
sugar transporter family, Stl1p is the glycerol/ $\mathrm{H}^{+}$symporter in Saccharomyces cerevisiae. Mol Biol Cell 16:2068-2076. https ://doi.org/10.1091/mbc.E04-10-0884

16. Fredlund E, Druvefors U, Boysen ME, Lingsten KJ, Schnurer J (2002) Physiological characteristics of the biocontrol yeast Pichia anomala J121. FEMS Yeast Res 2:395-402. https://doi. org/10.1111/j.1567-1364.2002.tb00109.x

17. Gao Z, Ma Y, Wang Q, Zhang M, Wang J, Liu Y (2016) Effect of crude glycerol impurities on lipid preparation by Rhodosporidium toruloides yeast 32489. Bioresour Technol 218:373-379. https:// doi.org/10.1016/j.biortech.2016.06.088

18. González-Hernández J (2010) Molecular cloning and characterization of STL1 gene of Debaryomyces hansenii. J Yeast and Fungal Res 1(4):62-72

19. Guerra JB, Araujo RA, Pataro C, Franco GR, Moreira ES, Mendonca-Hagler LC, Rosa CA (2001) Genetic diversity of Saccharomyces cerevisiae strains during the $24 \mathrm{~h}$ fermentative cycle for the production of the artisanal Brazilian cachaça. Lett Appl Microbiol 33:106-111. https://doi.org/10.1046/j.1472-765x.2001.00959.x

20. Ho PW, Klein M, Futschik M, Nevoigt E (2018) Glycerol positive promoters for tailored metabolic engineering of the yeast $\mathrm{Sac}$ charomyces cerevisiae. FEMS Yeast Res. https://doi.org/10.1093/ femsyr/foy019

21. Hong SH, Song YS, Seo DJ, Kim KY, Jung WJ (2017) Antifungal activity and expression patterns of extracellular chitinase and beta-1,3-glucanase in Wickerhamomyces anomalus EG2 treated with chitin and glucan. Microb Pathog 110:159-164. https://doi. org/10.1016/j.micpath.2017.06.038

22. Huerta-Cepas J, Szklarczyk D, Forslund K, Cook H, Heller D, Walter MC, Rattei T, Mende DR, Sunagawa S, Kuhn M, Jensen LJ, von Mering C, Bork P (2016) eggNOG 4.5: a hierarchical orthology framework with improved functional annotations for eukaryotic, prokaryotic and viral sequences. Nucleic Acids Res 44:D286-D293. https://doi.org/10.1093/nar/gkv1248

23. IRENA (2014) A working paper for REmap 2030. Global bioenergy - supply and demand projections agency IRE, Abu Dhabi, United Arab Emirates http://www.irena.org/-/media/Files/IRENA/ Agency/Publication/2014/IRENA_REmap_2030_Biomass_paper 2014.pdf

24. Kayingo G, Martins A, Andrie R, Neves L, Lucas C, Wong B (2009) A permease encoded by $S T L 1$ is required for active glycerol uptake by Candida albicans. Microbiology 155:1547-1557. https://doi.org/10.1099/mic.0.023457-0

25. Koutinas A, Vlysidis A, Pleissner D, Kopsahelis N, Lopez Garcia I, Kookos IK, Papanikolaou S, Kwan TH, Lin C (2014) Valorization of industrial waste and by-product streams via fermentation for the production of chemicals and biopolymers. Chem Soc Rev 43:2587-2627. https://doi.org/10.1039/c3cs60293a

26. Krogh A, Larsson B, von Heijne G, Sonnhammer EL (2001) Predicting transmembrane protein topology with a hidden Markov model: application to complete genomes. J Mol Biol 305:567580. https://doi.org/10.1006/jmbi.2000.4315

27. Kurita O (2008) Increase of acetate ester-hydrolysing esterase activity in mixed cultures of Saccharomyces cerevisiae and Pichia anomala. J Appl Microbiol 104:1051-1058. https://doi.org/10.11 11/j.1365-2672.2007.03625.x

28. Lages F, Lucas C (1995) Characterization of a glycerol/ $\mathrm{H}^{+}$symport in the halotolerant yeast Pichia sorbitophila. Yeast 11:111119. https://doi.org/10.1002/yea.320110203

29. Lages F, Lucas C (1997) Contribution to the physiological characterization of glycerol active uptake in Saccharomyces cerevisiae. Biochim Biophys Acta 1322:8-18

30. Lages F, Silva-Graca M, Lucas C (1999) Active glycerol uptake is a mechanism underlying halotolerance in yeasts: a study of 42 species. Microbiology 145(Pt 9):2577-2585. https://doi. org/10.1099/00221287-145-9-2577
31. Larsson C, Pahlman IL, Ansell R, Rigoulet M, Adler L, Gustafsson L (1998) The importance of the glycerol 3-phosphate shuttle during aerobic growth of Saccharomyces cerevisiae. Yeast 14:347-357. https://doi.org/10.1002/(sici)1097-0061(19980 315)14:4\%3c347:aid-yea226\%3e3.0.co;2-9

32. Leiva-Candia DE, Tsakona S, Kopsahelis N, Garcia IL, Papanikolaou S, Dorado MP, Koutinas AA (2015) Biorefining of byproduct streams from sunflower-based biodiesel production plants for integrated synthesis of microbial oil and value-added co-products. Bioresour Technol 190:57-65. https://doi.org/10.1016/j.biort ech.2015.03.114

33. Leoneti AB, Aragão-Leoneti V, de Oliveira SVWB (2012) Glycerol as a by-product of biodiesel production in Brazil: alternatives for the use of unrefined glycerol. Renew Energy 45:138-145. https ://doi.org/10.1016/j.renene.2012.02.032

34. Liu L-P, Zong M-H, Hu Y, Li N, Lou W-Y, Wu H (2017) Efficient microbial oil production on crude glycerol by Lipomyces starkeyi AS 2.1560 and its kinetics. Process Biochem (Oxford, UK) 58:230-238. https://doi.org/10.1016/j.procbio.2017.03.024

35. López V, Querol A, Ramón D, Fernández-Espinar MT (2001) A simplified procedure to analyse mitochondrial DNA from industrial yeasts. Int J Food Microbiol 68:75-81. https://doi. org/10.1016/S0168-1605(01)00483-4

36. Lucas C, Da Costa M, Van Uden N (1990) Osmoregulatory active sodium-glycerol co-transport in the halotolerant yeast Debaryomyces hansenii. Yeast 6:187-191. https://doi.org/10.1002/ yea. 320060303

37. Meher LC, Vidya Sagar D, Naik SN (2006) Technical aspects of biodiesel production by transesterification-a review. Renewable Sustainable Energy Rev 10:248-268. https://doi.org/10.1016/j. rser.2004.09.002

38. Melin P, Hakansson S, Eberhard TH, Schnurer J (2006) Survival of the biocontrol yeast Pichia anomala after long-term storage in liquid formulations at different temperatures, assessed by flow cytometry. J Appl Microbiol 100:264-271. https://doi.org/10.11 11/j.1365-2672.2005.02778.x

39. Merico A, Ragni E, Galafassi S, Popolo L, Compagno C (2011) Generation of an evolved Saccharomyces cerevisiae strain with a high freeze tolerance and an improved ability to grow on glycerol. J Ind Microbiol Biotechnol 38:1037-1044. https://doi. org/10.1007/s10295-010-0878-3

40. Minagawa N, Yoshimoto A (1987) The induction of cyanide-resistant respiration in Hansenula anomala. $\mathrm{J}$ Biochem 101:1141-1146

41. Mo EK, Sung CK (2014) Production of white pan bread leavened by Pichia anomala SKM-T. Food Sci Biotechnol 23:431-437. https://doi.org/10.1007/s10068-014-0059-7

42. Moore AL, Siedow JN (1991) The regulation and nature of the cyanide-resistant alternative oxidase of plant mitochondria. Biochim Biophys Acta 1059:121-140. https://doi.org/10.1016/S0005 $-2728(05) 80197-5$

43. Nevoigt E, Stahl U (1997) Osmoregulation and glycerol metabolism in the yeast Saccharomyces cerevisiae. FEMS Microbiol Rev 21:231-241. https://doi.org/10.1111/j.1574-6976.1997.tb00352.x

44. Niu C, Yuan Y, Hu Z, Wang Z, Liu B, Wang H, Yue T (2016) Accessing spoilage features of osmotolerant yeasts identified from kiwifruit plantation and processing environment in Shaanxi, China. Int J Food Microbiol 232:126-133. https://doi. org/10.1016/j.ijfoodmicro.2016.03.012

45. Ochoa-Estopier A, Lesage J, Gorret N, Guillouet SE (2011) Kinetic analysis of a Saccharomyces cerevisiae strain adapted for improved growth on glycerol: implications for the development of yeast bioprocesses on glycerol. Bioresour Technol 102:15211527. https://doi.org/10.1016/j.biortech.2010.08.003

46. OECD/FAO (2015) OECD-FAO agricultural outlook 2015. OECD Publishing, Paris. https://doi.org/10.1787/agr_outlook-2015-en 
47. Oleoline (2017) Glycerin market report. quarterly glycerine market report, Hong Kong. http://www.hbint.com/datas/media/59020 4fd077a6e381ef1a252/sample-quarterly-glycerine.pdf

48. Oliveira R, Lages F, Silva-Graca M, Lucas C (2003) Fps1p channel is the mediator of the major part of glycerol passive diffusion in Saccharomyces cerevisiae: artefacts and re-definitions. Biochim Biophys Acta 1613:57-71. https://doi.org/10.1016/S0005 -2736(03)00138-X

49. Oro L, Feliziani E, Ciani M, Romanazzi G, Comitini F (2018) Volatile organic compounds from Wickerhamomyces anomalus, Metschnikowia pulcherrima and Saccharomyces cerevisiae inhibit growth of decay causing fungi and control postharvest diseases of strawberries. Int J Food Microbiol 265:18-22. https://doi. org/10.1016/j.jifoodmicro.2017.10.027

50. Passoth V, Fredlund E, Druvefors UA, Schnurer J (2006) Biotechnology, physiology and genetics of the yeast Pichia anomala. FEMS Yeast Res 6:3-13. https://doi.org/10.111 1/j.1567-1364.2005.00004.x

51. Pereira I, Madeira A, Prista C, Loureiro-Dias MC, Leandro MJ (2014) Characterization of new polyol/ $\mathrm{H}^{+}$symporters in Debaryomyces hansenii. PLoS ONE 9:e88180. https://doi.org/10.1371/ journal.pone.0088180

52. Pfaffl MW (2001) A new mathematical model for relative quantification in real-time RT-PCR. Nucleic Acids Res 29:e45. https:// doi.org/10.1093/nar/29.9.e45

53. Riley R, Haridas S, Wolfe KH, Lopes MR, Hittinger CT, Goker M, Salamov AA, Wisecaver JH, Long TM, Calvey CH, Aerts AL, Barry KW, Choi C, Clum A, Coughlan AY, Deshpande S, Douglass AP, Hanson SJ, Klenk HP, LaButti KM, Lapidus A, Lindquist EA, Lipzen AM, Meier-Kolthoff JP, Ohm RA, Otillar RP, Pangilinan JL, Peng Y, Rokas A, Rosa CA, Scheuner C, Sibirny AA, Slot JC, Stielow JB, Sun H, Kurtzman CP, Blackwell M, Grigoriev IV, Jeffries TW (2016) Comparative genomics of biotechnologically important yeasts. Proc Natl Acad Sci U S A 113:9882-9887. https://doi.org/10.1073/pnas.1603941113

54. Saier MH (1999) Eukaryotic transmembrane solute transport systems. In: Jeon KW (ed) International review of cytology, vol 190. Academic Press, New York, pp 61-136. https://doi.org/10.1016/ S0074-7696(08)62146-4

55. Sakajo S, Minagawa N, Yoshimoto A (1993) Characterization of the alternative oxidase protein in the yeast Hansenula anomala. FEBS Lett 318:310-312. https://doi.org/10.1016/00145793(93)80535-3

56. Sakajo S, Minagawa N, Yoshimoto A (1999) Structure and regulatory expression of a single copy alternative oxidase gene from the yeast Pichia anomala. Biosci Biotechnol Biochem 63:1889-1894. https://doi.org/10.1271/bbb.63.1889

57. Schneider J, Rupp O, Trost E, Jaenicke S, Passoth V, Goesmann A, Tauch A, Brinkrolf K (2012) Genome sequence of Wickerhamomyces anomalus DSM 6766 reveals genetic basis of biotechnologically important antimicrobial activities. FEMS Yeast Res 12:382-386. https://doi.org/10.1111/j.1567-1364.2012.00791.x

58. Sherman F (2002) Getting started with yeast. In: Guthrie C, Fink GR (eds) Methods in enzymology, vol 350. Academic Press, New York, pp 3-41. https://doi.org/10.1016/S0076-6879(02)50954-X

59. Siderius M, Van Wuytswinkel O, Reijenga KA, Kelders M, Mager WH (2000) The control of intracellular glycerol in Saccharomyces cerevisiae influences osmotic stress response and resistance to increased temperature. Mol Microbiol 36:1381-1390. https://doi. org/10.1046/j.1365-2958.2000.01955.x

60. Singh MV, Anthony Weil P (2002) A method for plasmid purification directly from yeast. Anal Biochem 307:13-17. https://doi. org/10.1016/S0003-2697(02)00018-0

61. Souza KS, Ramos CL, Schwan RF, Dias DR (2017) Lipid production by yeasts grown on crude glycerol from biodiesel industry. Prep Biochem Biotechnol 47:357-363. https://doi. org/10.1080/10826068.2016.1244689

62. Souza KST, Gudina EJ, Azevedo Z, de Freitas V, Schwan RF, Rodrigues LR, Dias DR, Teixeira JA (2017) New glycolipid biosurfactants produced by the yeast strain Wickerhamomyces anomalus CCMA 0358. Colloids Surf B 154:373-382. https:// doi.org/10.1016/j.colsurfb.2017.03.041

63. Spier F, Buffon JG, Burkert CAV (2015) Bioconversion of raw glycerol generated from the synthesis of biodiesel by different oleaginous yeasts: lipid content and fatty acid profile of biomass. Indian J Microbiol 55:415-422. https://doi.org/10.1007/s1208 8-015-0533-9

64. Swinnen S, Ho PW, Klein M, Nevoigt E (2016) Genetic determinants for enhanced glycerol growth of Saccharomyces cerevisiae. Metab Eng 36:68-79. https://doi.org/10.1016/j.ymben .2016 .03 .003

65. Swinnen S, Klein M, Carrillo M, McInnes J, Nguyen HTT, Nevoigt E (2013) Re-evaluation of glycerol utilization in Saccharomyces cerevisiae: characterization of an isolate that grows on glycerol without supporting supplements. Biotechnol Biofuels 6:157. https://doi.org/10.1186/1754-6834-6-157

66. Thomik T, Wittig I, Choe JY, Boles E, Oreb M (2017) An artificial transport metabolon facilitates improved substrate utilization in yeast. Nat Chem Biol 13:1158-1163. https://doi.org/10.1038/ nchembio. 2457

67. Tulha J, Carvalho J, Armada R, Faria-Oliveira F, Lucas C, Pais C, Almeida J, Ferreira C (2012) Yeast, the man's best friend. In: Benjamin Valdez RZ, Schorr M (ed) Scientific, health and social aspects of the food industry. INTECH Open Access Publisher, Instituto de Ingeniería, Universidad Autónoma de Baja California, Mexicali, México. https://doi.org/10.5772/31471

68. Tusnady GE, Simon I (2001) The HMMTOP transmembrane topology prediction server. Bioinformatics (Oxford, England) 17:849-850

69. Veiga A, Arrabaca JD, Loureiro-Dias MC (2000) Cyanide-resistant respiration is frequent, but confined to yeasts incapable of aerobic fermentation. FEMS Microbiol Lett 190:93-97. https:// doi.org/10.1111/j.1574-6968.2000.tb09268.x

70. Vickers CE, Bydder SF, Zhou Y, Nielsen LK (2013) Dual gene expression cassette vectors with antibiotic selection markers for engineering in Saccharomyces cerevisiae. Microb Cell Fact 12:96. https://doi.org/10.1186/1475-2859-12-96

71. Wahyono A, Kang W-W, H-d Park (2015) Characterization and application of Torulaspora delbrueckii JK08 and Pichia anomala JK04 as baker's yeasts. J Food Nutr Res (Bratislava, Slovakia) 54:205-207

72. Wallace-Salinas V, Signori L, Li Y-Y, Ask M, Bettiga M, Porro D, Thevelein JM, Branduardi P, Foulquié-Moreno MR, GorwaGrauslund M (2014) Re-assessment of YAP1 and MCR1 contributions to inhibitor tolerance in robust engineered Saccharomyces cerevisiae fermenting undetoxified lignocellulosic hydrolysate. AMB Express 4:56. https://doi.org/10.1186/s13568-014-0056-5

73. Wojda I, Alonso-Monge R, Bebelman JP, Mager WH, Siderius M (2003) Response to high osmotic conditions and elevated temperature in Saccharomyces cerevisiae is controlled by intracellular glycerol and involves coordinate activity of MAP kinase pathways. Microbiology 149:1193-1204. https://doi.org/10.1099/ mic.0.26110-0

74. Yachdav G, Kloppmann E, Kajan L, Hecht M, Goldberg T, Hamp T, Honigschmid P, Schafferhans A, Roos M, Bernhofer M, Richter L, Ashkenazy H, Punta M, Schlessinger A, Bromberg Y, Schneider R, Vriend G, Sander C, Ben-Tal N, Rost B (2014) PredictProtein-an open resource for online prediction of protein structural and functional features. Nucleic Acids Res 42:W337-W343. https ://doi.org/10.1093/nar/gku366 
75. Yazdani SS, Gonzalez R (2007) Anaerobic fermentation of glycerol: a path to economic viability for the biofuels industry. Curr Opin Biotechnol 18:213-219. https://doi.org/10.1016/j.copbi o.2007.05.002

76. Zimmermann L, Stephens A, Nam SZ, Rau D, Kubler J, Lozajic M, Gabler F, Soding J, Lupas AN, Alva V (2017) A completely reimplemented MPI bioinformatics toolkit with a new HHpred server at its core. J Mol Biol. https://doi.org/10.1016/j. jmb.2017.12.007
Publisher's Note Springer Nature remains neutral with regard to jurisdictional claims in published maps and institutional affiliations. 